\title{
PERANCANGAN AUGMENTED REALITY SEBAGAI ALAT BANTU EDUKASI PELAJARAN SEJARAH DI INDONESIA BAGI SISWA SMP
}

\author{
Varian Dine Mejiro, Peter Rhian Gunawan, Elizabeth Wianto \\ (Email: variandine512@gmail.com) \\ Jurusan Desain Komunikasi Visual \\ Fakultas Seni Rupa dan Desain \\ Universitas Kristen Maranatha \\ JL. Prof. Drg. Surya Sumantri No.65, Bandung, Jawa Barat, 40164, Indonesia
}

\begin{abstract}
ABSTRAK
Sejarah merupakan mata pelajaran wajib pada kurikulum sekolah formal di Indonesia. Melalui pelajaran sejarah, siswa dapat memahami dan mengetahui adanya peristiwa-peristiwa yang akhirnya dapat menumbuhkan nilai budaya dan menjadi landasan kemajuan suatu bangsa. Apalagi Indonesia merupakan negara yang memiliki sejarah panjang, salah satunya adalah mengenai kerajaan-kerajaan yang tumbuh dan berkembang di wilayah Indonesia. Sayangnya, pelajaran sejarah kurang disukai oleh kebanyakan siswa Sekolah Menengah Pertama, karena metodenya yang monoton. Oleh karena itu, tujuan dari perancangan ini adalah untuk membuat media interaktif pembelajaran sejarah di Sekolah Menengah Pertama yang hingga saat ini masih menggunakan metode berfokus pada guru. Kemajuan teknologi dan perubahan kebiasaan anak dalam memahami sesuatu dengan cara bermain, menjadi landasan konsep pembuatan media permainan bertemakan sejarah. Media interaktif tersebut adalah permainan papan yang dipadukan dengan teknologi Augmented Reality untuk menambah daya tarik permainan. Augmented Reality dapat memberikan pengalaman dalam bermain sehingga siswa dapat merasakan kesan nyata dalam permainan. Selain papan permainan sebagai media utamanya, digunakan juga media promosi sebagai media pendukung berupa $x$-banner, iklan di media sosial seperti facebook dan instagram. Melalui perancangan media interaktif berupa permainan papan, diharapkan para siswa dapat lebih memahami pembelajaran Kerajaan Hindu Buddha di Indonesia dan tidak merasa bosan saat belajar.
\end{abstract}

Kata Kunci: alat bantu edukasi; augmented reality; papan permainan; pelajaran sejarah

\begin{abstract}
History is a compulsory subject in the formal school curriculum in Indonesia. Through history lessons, students can understand and know the existence of events that eventually can foster cultural values and become the foundation of the progress of a nation. Moreover, Indonesia is a country that has a long history, one of the topics are about kingdoms that once grow and develop in the territory of Indonesia. Unfortunately, history lessons are unfavored by most junior high school students, because of their monotonous methods. Therefore, the purpose of this design is to create an interactive media for learning history in Junior High School, which until now still using teacher center learning method. Technological advances and changes in children's habits in understanding something by playing became the foundation of the concept of making history game. Interactive media created is a board game combined with Augmented Reality technology to add immersion in the game. Augmented Reality can provide experience in playing so that students can feel a real impression in the game. In addition to the game board as the primary media, used as well as media campaigns supporting the form of $x$-banner, advertising on social media such as Facebook and Instagram. Through the board games, students are expected to better understand the learning of the Hindu Buddhist Kingdom in Indonesia and not feel bored while studying.
\end{abstract}

Keywords: a history lesson; educational aids; augmented reality; board games 


\section{PENDAHULUAN}

Sejarah adalah mata pelajaran wajib yang perlu dipelajari oleh siswa mulai dari tingkat Sekolah Dasar hingga Sekolah Menengah Atas. Saat mempelajari sejarah, diharapkan siswa dapat memahami dan mendapat banyak pelajaran berharga dari peristiwa bersejarah yang pernah terjadi di Indonesia. Terlebih lagi, pada masa lampau Indonesia adalah negara dengan banyak kerajaan yang merupakan cikal bakal masuknya berbagai macam budaya, tata cara perekonomian, dan kehidupan sosial bangsa. Melalui sejarah juga dapat dikembangkan nilai-nilai kehidupan sosial bagi siswa seperti nilai budaya dan filosofi yang akan memperkaya bangsa manakala bangsa itu di kemudian hari akan menjadi bangsa yang maju.

Salah satu hasil penelitian mengenai faktor penyebab kejenuhan belajar sejarah dikarenakan siswa lelah akibat mencatat dan susahnya berkonsentrasi pada materi yang terlalu banyak serta ditambah kebosanan karena metode pemberian ceramah dan tugas yang tidak variatif (Fauziah, 2013: 100-106). Upaya yang dilakukan oleh Nelly Indriani Widiastuti, seorang guru, untuk mengatasi masalah di atas, beliau telah melakukan metode yang bervariatif dan pembelajaran di luar kelas yaitu dengan cara membuat perancangan game edukasi sejarah dengan materi pelajaran yang cenderung dianggap terlalu luas, rumit dan banyak hafalan (Widiastuti, 2012: 41). Sebagai pelengkap cara edukasi di atas melalui keilmuan Desain Komunikasi Visual (DKV), pelajaran Sejarah bagi anak Sekolah Menengah Pertama dapat dibuat lebih menarik lagi, yaitu dengan salah satu media interaktif berteknologi era digital berupa Augmented Reality (AR). Metode pembelajaran dengan alat bantu yang bersifat interaktif ini diharapkan dapat menunjang partisipasi anak dalam belajar, sehingga capaian pembelajaran dapat dengan lebih mudah dicapai.

\section{METODE PERANCANGAN}

Perancangan alat bantu pembelajaran sejarah ini dilakukan dengan metode kualitatif dan kuantitatif. Metode kualitatif melalui wawancara tidak terstruktur kepada guru dan siswa Sekolah Menengah Pertama di Kota Bandung untuk mengetahui permasalahan dalam proses pembelajaran sejarah dalam kelas dan kendala yang dihadapi para siswa saat belajar sejarah. Selain itu diperkuat dengan data kuantitatif yang diperoleh melalui kuesioner kepada 100 (seratus) orang responden, yaitu para siswa SMP di Bandung untuk mengetahui topik sejarah yang sulit dipahami dan bagaimana upaya mengatasinya. Hal ini 
dilakukan untuk mengetahui media bantu pembelajaran yang sesuai.

Pada perancangan ini juga dilakukan studi pustaka guna mengumpulkan data dan informasi dari sumber-sumber terpercaya serta mencari teori yang mendukung pada perancangan ini. Teori yang digunakan adalah:

1. Teori pembelajaran

Teori pembelajaran menekankan pada dua gagasan, yaitu:

A. Teori pembelajaran terkait teori dari Vygotsky (DeVries, 2000:195) yang menekankan bahwa proses belajar dipengaruhi oleh perilaku bersifat stimulus respon. Hal ini ditekankan melalui perilaku yang mulai dapat diikuti oleh siswa yang berada pada usia sekolah (mulai 7 tahun ke atas).

B. Teori pembelajaran terkait teori dari Piaget (DeVries, 2000: 202) yang menekankan pada proses belajar dipengaruhi oleh hubungan berbasis respek dan kerjasama. Walaupun siswa dan guru tidak 'sama' dalam hubungan sosial, tetapi program yang bersifat lebih 'ramah' dan praktik dapat dianggap lebih berhasil.

2. Teori Game

Teori game yang digunakan adalah menekankan pada teori game dari Kevin Leyton Brown mengenai hak yang harus didapatkan para pemain game untuk mendapatkan pengalaman yang menarik dalam bermain (Brown, 2008).

3. Teori llustrasi

Gambar merupakan bentuk komunikasi yang harus diperhatikan. Sebuah gambar harus memperhatikan detail proporsi, warna, perspektif dan bentuk agar dapat menjadi indah untuk dinikmati ( Wallschlaeger, 1992).

\section{PEMBAHASAN}

Metode pembelajaran sejarah dalam kelas sangat mempengaruhi hasil belajar anak. Semakin banyak materi yang diberikan guru dalam belajar, para siswa akan merasa bosan dan tidak bersemangat untuk belajar. Berdasarkan hasil wawancara kepada guru Sekolah Menengah Pertama, diketahui bahwa siswa kurang bersemangat belajar sejarah karena materi yang padat serta mengandung peristiwa yang panjang, sehingga otomatis melahirkan banyak hafalan. Dalam pelajaran Sejarah di SMP, diketahui bahwa ada tiga topik besar yang ditawarkan sejak kelas 7 dan diulang pada kelas 9, yaitu tentang Kerajaan Hindu-Buddha di Indonesia, Kemerdekaan Indonesia, dan Tokoh Nasional Indonesia. Secara 
kognitif, topik Kerajaan Hindu-Buddha yang perlu dipahami secara komprehensif merupakan materi yang menempati porsi paling banyak. Oleh karena itu, studi kasus yang diambil dalam perancangan ini adalah materi pelajaran Kerajaan Hindu Buddha di Indonesia. Selaras dengan informasi yang diperoleh ketika wawancara dengan guru SMP, hasil kuesioner kepada 100 orang siswa juga menunjukkan hasil serupa. Diketahui bahwa $55 \%$ responden merasa bosan dan sulit ketika mempelajari sejarah, $89 \%$ responden menyatakan bahwa materi yang paling sulit adalah mengenai Kerajaan Hindu-Buddha, $58 \%$ responden menyatakan bahwa kendala yang dihadapi dalam mempelajari sejarah adalah cara pengajaran yang tidak menarik, dan 52\% responden menganggap bahwa sistem pembelajaran yang disukai adalah dengan belajar sambil bermain. Seluruh kuesioner dilakukan dengan pertanyaan bersifat pilihan ganda yang dapat dipilih lebih dari satu sehingga setiap jawaban secara langsung dapat mewakili opini responden.

Target dari alat bantu edukasi sejarah dalam bentuk permainan interaktif ini adalah anak berusia 12-15 tahun yang masih duduk di bangku Sekolah Menengah Pertama dan mengalami kendala saat belajar sejarah dengan topik Kerajaan Hindu Buddha di Indonesia.

Media interaktif yang dimaksud, adalah board game (permainan papan) yang ditambahkan unsur Augmented Reality sebagai bagian dari era digital yang mampu menyajikan visualisasi objek sehingga terlihat lebih nyata dalam perangkat gadget. Augmented Reality yang disertakan, merupakan media baru yang dapat menjadi daya tarik dan pengalaman bermain anak. Penambahan Augmented Reality sebagai salah satu komponen tambahan merupakan upaya untuk membedakan elemen permainan yang perlu diperhatikan dengan lebih seksama karena satu dan lain hal. Misalnya karena objeknya masih ada (candi), atau agar objeknya dapat dengan mudah dikenali daripada hanya melalui tulisan saja (namanama raja). Penambahan fitur Augmented Reality sekaligus merupakan elemen asosiatif tambahan yang dapat mempermudah siswa untuk mengingat objek yang dimaksud.

Konsep edukasi yang digunakan adalah dengan memperkenalkan permainan edukasi yang tujuanya sebagai media pembantu pembelajaran dan dapat menambahkan wawasan. Kerajaan Hindu Buddha yang dirancang adalah Kerajaan Majapahit, karena Kerajaan ini termasuk dalam kerajaan yang terbesar dan rentang masanya cukup panjang. di Indonesia. 
Permainan papan ini menceritakan tentang sekelompok siswa dan siswi Sekolah Menengah Pertama yang terjebak dalam masa lalu dan harus berusaha untuk meloloskan diri. Agar mereka dapat lolos para pemain harus berusaha menyelesaikan semua misi yang sudah ditentukan dalam permainan. Dalam permainan ini terdapat beberapa kartu yang berisi pengetahuan mengenai Kerajaan Majapahit, kartu tersebut bertujuan sebagai bekal wawasan dalam permainan dan dapat digunakan untuk menyerang sesama pemain dalam permainan. Konsep yang digunakan adalah berpetualang agar dapat menggambarkan penempatan yang belum dikenal sebelumnya oleh para siswa dan pengalaman menjelajahi wilayah Kerajaan Majapahit.

Permainan akan berlangsung dalam tiga stage yang dinamai dengan 'masa'. Setiap masa menandai tahapan tertentu pada perkembangan Kerajaan Majapahit yang dianggap signifikan.

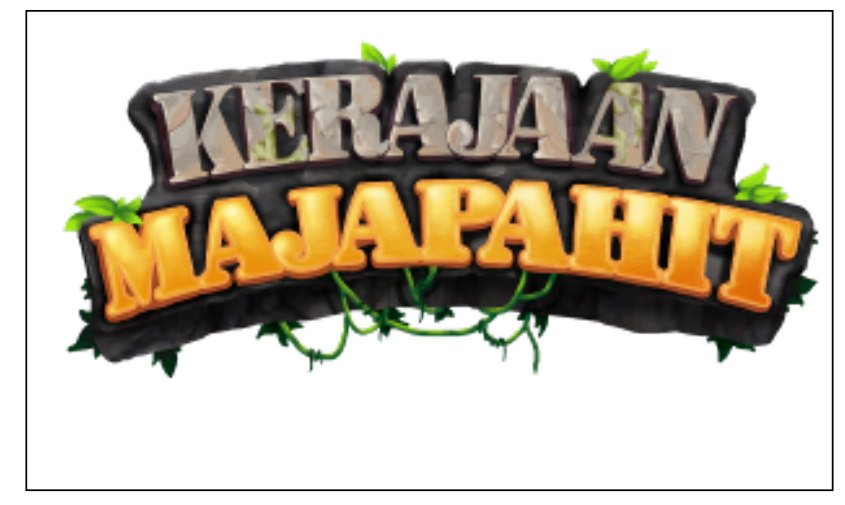

Gambar 1. Logo Permainan

(Sumber: Data Penulis, 2018)

Logo permainan ini menggunakan font Stencil sebagai dasar pembuatan visual logo. Penggambaran logo dengan unsur batu alam pada tulisan KERAJAAN menggambarkan kesan masa lampau kerajaan yang struktur bangunannya masih menggunakan bahan batu alam. Penulisan Majapahit menggunakan warna emas agar asosiatif dengan kejayaan Kerajaan Majapahit pada masa pemerintahan Hayam Wuruk. 


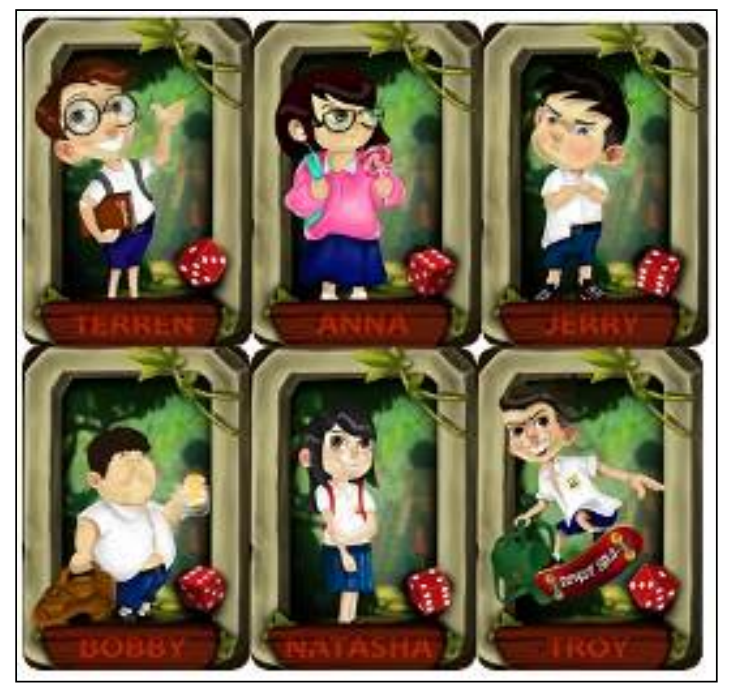

Gambar 2. Kartu Karakter Permainan (Sumber: Data Penulis,2018)

Konsep desain kartu karakter permainan adalah penggambaran karakter disesuaikan dengan gambaran anak Sekolah Menengah Pertama dan digabungkan dengan unsur masa lampau menggunakan layout yang menggunakan efek kertas lapuk agar sesuai dengan topik permainan sejarah.
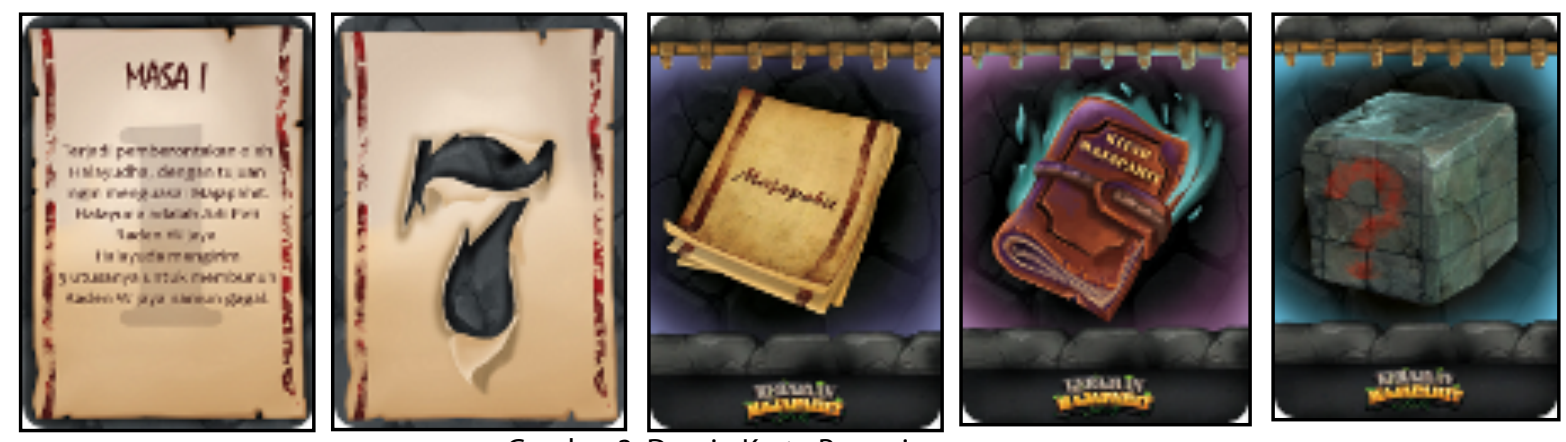

Gambar 3. Desain Kartu Permainan

(Sumber: Data Penulis, 2018)

Dalam permainan ini, elemen permainan papan seperti kartu pada gambar bertujuan untuk menuliskan informasi permainan. Terdapat 3 kartu berisikan pengetahuan dalam permainan ini, yaitu :

1. Kartu masayang berisikan informasi mengenai proses terbentuknya Kerajaan Majapahit dan peristiwa penting yang terjadi. Isi dari informasi kartu masa ini sesuai dengan kurikulum pembelajaran sekarang.

2. Kartu Kitab peninggalan Kerajaan Majapahit yang berisikan kitab-kitab peninggalan Kerajaan agar para siswa memahami peninggalan Kitab pada masa Kerajaan Majapahit.

3. Kartu Candi yang berisikan informasi berupa Augmented Reality candi-candi peninggalan kerajaan majapahit berupa visual 3 dimensi yang harus dipindai 
menggunakan gadget untuk mendapatkan kenampakan bangunan candi dan informasi di dalamnya.

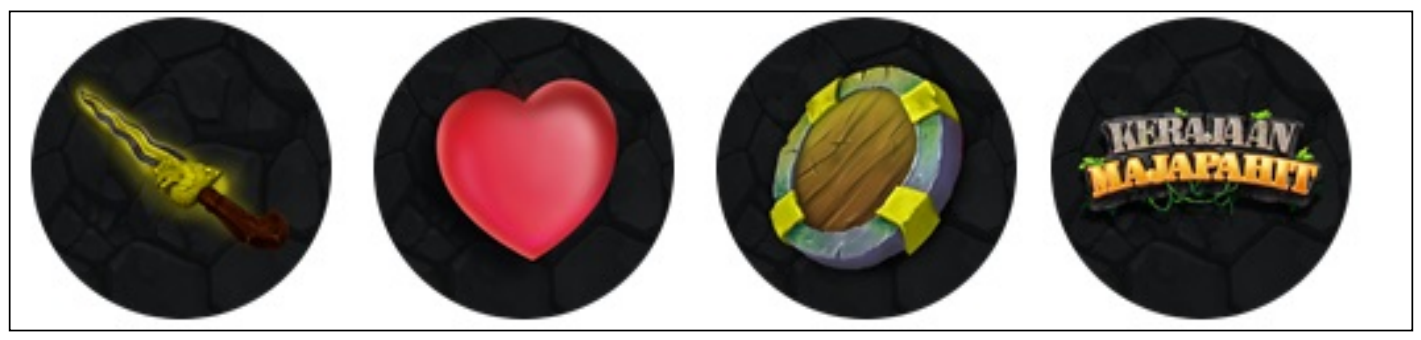

Gambar 4. Desain Token

(Sumber: Data Penulis, 2018)

Token bertujuan sebagai penanda untuk membatasi kemampuan para pemain. Terdapat 3 token dalam permainan, yaitu: (1) token keris sebagai penanda pemain dapat menyerang pemain lain; (2) token nyawa sebagai penanda nyawa dalam permainan; dan (3) token tameng sebagai penanda pemain tidak dapat diserang pemain lain.

Terdapat dua elemen yang dirancang dengan desain tiga dimensi dengan Augmented Reality, karena dianggap sebagai elemen vital dalam memahami sejarah Kerajaan Majapahit, sehingga selain lebih diistimewakan, efek ini juga menjadi tambahan elemen asosiatif yang memudahkan siswa untuk mengingat objek yang dimaksud. Penekanan ini sesuai dengan metode asosiasi benda yang secara umum dikenal sebagai salah satu metode belajar. Secara asosiatif, maka bentuk ikonik dari benda (terutama untuk candi) akan dapat mempermudah siswa dalam mengingat bentuk penyederhanaan dibandingkan dengan bentuk aslinya apabila kelak meninjau situs aslinya.

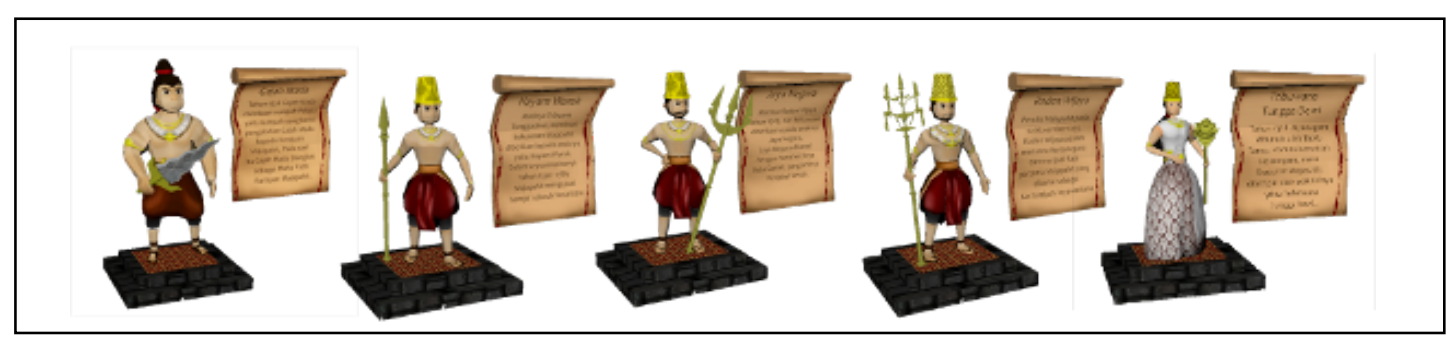

Gambar 5. Karakter Augmented Reality (Sumber: Data Penulis, 2018)

Peran penting tokoh yang memengaruhi perkembangan Kerajaan Majapahit merupakan alasan karakter berjenis ini dipilih dengan tambahan efek Augmented Reality. Contohnya, pada karakter paling kiri pada Gambar 5, diberikan penggambaran Gajah Mada, yaitu seorang mahapatih Kerajaan Majapahit yang terkenal dengan Sumpah Palapa. Sumpah 
Palapa dan Gajah Mada lekat dengan simbol persatuan nusantara dan nasionalisme Indonesia, sehingga kini secara umum Gajah Mada dikenal sebagai salah satu Pahlawan Indonesia. Pada masa pengabdiannya, Majapahit berada dalam masa keemasan dibawah kepemimpinan Hayam Wuruk.

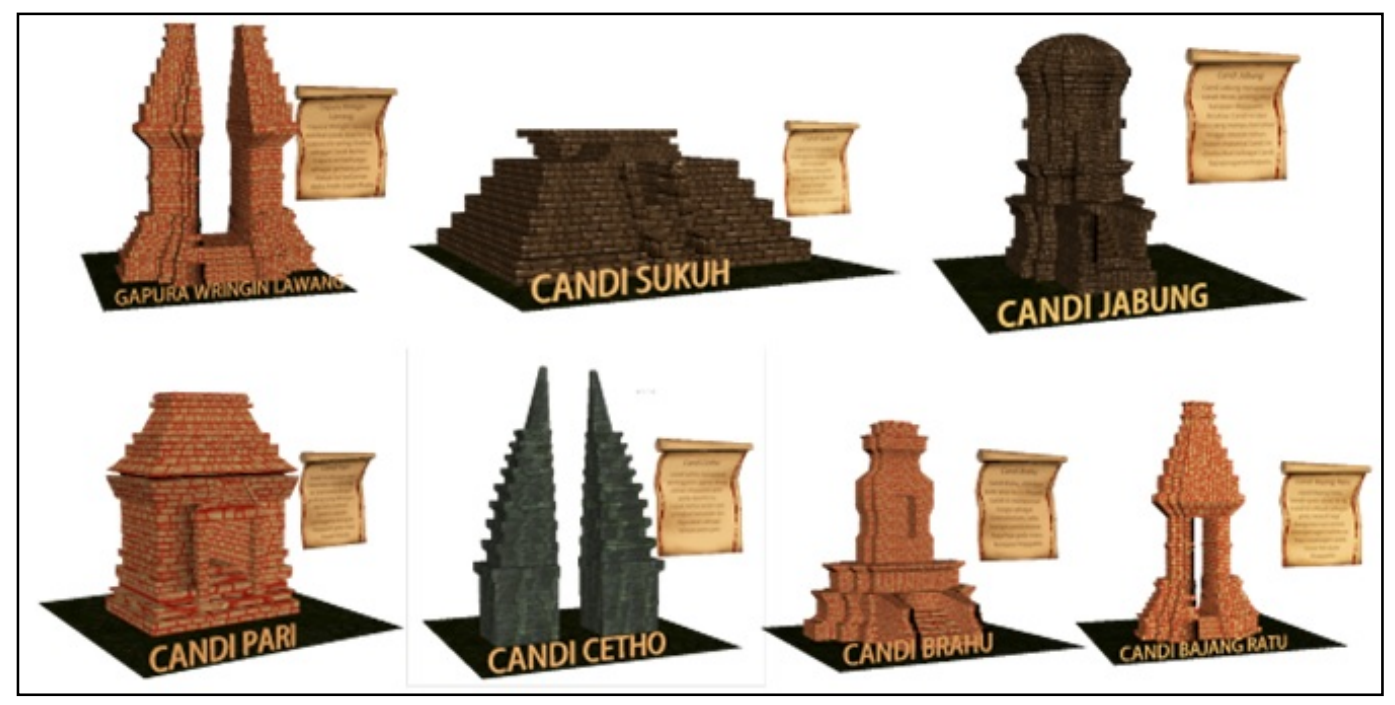

Gambar 6. Candi Augmented Reality (Sumber: Data Penulis, 2018)

Candi juga dirancang dengan desain tiga dimensi. Melalui penggambaran tiga dimensi dengan efek Augmented Reality, maka para siswa dapat mengenali gambaran candi-candi pada masa Kerajaan Majapahit tanpa harus mendatangi lokasi candi tersebut. Tabel 1 menunjukkan keterangan mengenai candi-candi secara singkat.

Tabel 1. Keterangan Candi

\begin{tabular}{|l|l|l|l|l|l|}
\hline No & $\begin{array}{l}\text { Nama } \\
\text { Candi }\end{array}$ & Letak & Fungsi & Karakteristik & $\begin{array}{l}\text { Perkiraan waktu } \\
\text { pembangunan }\end{array}$ \\
\hline 1. & $\begin{array}{l}\text { Candi } \\
\text { Wringin } \\
\text { Lawang } \\
\text { (Gapura } \\
\text { Wringin } \\
\text { Lawang) }\end{array}$ & $\begin{array}{l}\text { Jawa Timur, } \\
\text { Dukuh Wringin } \\
\text { Lawang, Desa Jati } \\
\text { Pasar, Kecamatan } \\
\text { Trowulan, } \\
\text { Kabupaten } \\
\text { Mojokerto. }\end{array}$ & $\begin{array}{l}\text { Diperkirakan sebagai } \\
\text { gerbang masuk ke } \\
\text { Kerajaan Majapahit } \\
\text { dan bentuknya } \\
\text { sekarang diduplikat } \\
\text { menjadi gerbang } \\
\text { masuk menuju } \\
\text { provinsi Jawa Timur }\end{array}$ & $\begin{array}{l}\text { Dibuat dari batu } \\
\text { bata merah, } \\
\text { tampak seperti } \\
\text { candi yang } \\
\text { terbelah menjadi } \\
\text { dua dan } \\
\text { direnggangkan (= } \\
\text { bentuk Candi } \\
\text { Bentar/ Gapura } \\
\text { Gapit/ Gapura } \\
\text { Belah). Tingginya } \\
\text { kurang lebih 15 } \\
\text { meter }\end{array}$ & - \\
& & & & \\
\hline
\end{tabular}




\begin{tabular}{|c|c|c|c|c|c|}
\hline 2. & $\begin{array}{l}\text { Candi } \\
\text { Sukuh }\end{array}$ & $\begin{array}{l}\text { Jawa Tengah, di } \\
\text { lereng barat } \\
\text { Gunung Lawu, di } \\
\text { Dusun Sukuh, } \\
\text { Desa Berjo, } \\
\text { Kecamatan } \\
\text { Ngargoyoso, } \\
\text { Kabupaten } \\
\text { Karanganyar }\end{array}$ & $\begin{array}{l}\text { Pengruwatan, yaitu } \\
\text { untuk menangkal } \\
\text { atau melepaskan } \\
\text { kekuatan buruk yang } \\
\text { memengaruhi } \\
\text { kehidupan } \\
\text { seseorang. }\end{array}$ & $\begin{array}{l}\text { Candi Agama } \\
\text { Hindu, memiliki } \\
\text { teras berundak } \\
\text { (seperti punden } \\
\text { berundak pada } \\
\text { masa pra-Hindu), } \\
\text { menghadap ke } \\
\text { barat. Kompleks } \\
\text { candi menempati } \\
\text { areal seluas } 5.500 \\
\text { m2. }\end{array}$ & $\begin{array}{l}\text { Akhir abad ke- } \\
15\end{array}$ \\
\hline 3. & $\begin{array}{l}\text { Candi } \\
\text { Pari }\end{array}$ & $\begin{array}{l}\text { Jawa Timur, } \\
\text { Porong, } \\
\text { Kabupaten } \\
\text { Sidoarjo }\end{array}$ & $\begin{array}{l}\text { Penghormatan } \\
\text { kepada suami-istri } \\
\text { bernama Jaka } \\
\text { Pandelegan dan } \\
\text { Dewi Lara Walang } \\
\text { Angin. }\end{array}$ & $\begin{array}{l}\text { Candi Agama } \\
\text { Hindu, memiliki } 14 \\
\text { arca yang kini } \\
\text { disimpan di } \\
\text { Museum Nasional } \\
\text { Jakarta. Dibuat } \\
\text { dari batu bata dan } \\
\text { sedikit bagian } \\
\text { yang dibuat dari } \\
\text { batu andesit. }\end{array}$ & $\begin{array}{l}1371 \text { M (1293 } \\
\text { Saka) }\end{array}$ \\
\hline 4. & $\begin{array}{l}\text { Candi } \\
\text { Cetho }\end{array}$ & $\begin{array}{l}\text { Jawa Tengah, } \\
\text { Desa Gumeng, } \\
\text { Kabupaten } \\
\text { Karanganyar }\end{array}$ & Pengruwatan & $\begin{array}{l}\text { Candi Agama } \\
\text { Hindu, terletak di } \\
\text { ketinggian } \\
\text { 1400mdpl. } \\
\text { Arsitekturnya } \\
\text { seperti punden } \\
\text { berundak mirip } \\
\text { dengan Candi } \\
\text { Sukuh. Dibuat dari } \\
\text { batu andesit }\end{array}$ & Abad ke-15 \\
\hline 5. & $\begin{array}{l}\text { Candi } \\
\text { Brahu }\end{array}$ & $\begin{array}{l}\text { Jawa Timur, } \\
\text { Dukuh Jambu } \\
\text { Mente, Desa } \\
\text { Bejijong, } \\
\text { Kecamatan } \\
\text { Trowulan, } \\
\text { Kabupaten } \\
\text { Mojokerto. }\end{array}$ & $\begin{array}{l}\text { Diakui oleh } \\
\text { masyarakat sekitar } \\
\text { sebagai tempat } \\
\text { pembakaran jenasah } \\
\text { raja-raja Brawijaya } \\
\text { (tetapi diragukan } \\
\text { karena tidak ada } \\
\text { bekas abu/ mayat } \\
\text { karena bilik candi } \\
\text { sudah kosong) }\end{array}$ & $\begin{array}{l}\text { Candi Agama } \\
\text { Buddha, memiliki } \\
\text { profil alas stupa di } \\
\text { sisi Tenggara. } \\
\text { Menghadap ke } \\
\text { arah Barat } 18 \mathrm{x} \\
22.5 \text { m dengan } \\
\text { tinggi sekitar } 20 \\
\text { m. Dibuat dari } \\
\text { batu bata merah }\end{array}$ & Abad ke-15 \\
\hline 6. & $\begin{array}{l}\text { Candi } \\
\text { Bajang } \\
\text { Ratu }\end{array}$ & $\begin{array}{l}\text { Jawa Timur, } \\
\text { Dukuh Kraton, } \\
\text { Desa Temon, } \\
\text { Kecamatan } \\
\text { Trowulan, } \\
\text { Kabupaten } \\
\text { Mojokerto }\end{array}$ & $\begin{array}{l}\text { Penghormatan } \\
\text { kepada Jayanegara, } \\
\text { atau sebagai salah } \\
\text { satu pintu gerbang } \\
\text { Keraton Majapahit }\end{array}$ & $\begin{array}{l}\text { Dibuat dari batu } \\
\text { bata merah, } \\
\text { menghadap ke } \\
\text { Timur dan Barat, } \\
\text { dimensi } 16.1 \mathrm{~m} \\
\text { (tinggi) dan } 6.74 \\
\mathrm{~m} \text { (panjang) }\end{array}$ & Abad ke-13/14 \\
\hline
\end{tabular}

Sumber:Kepustakaan Candi (http://candi.perpusnas.go.id), Candi Wringin Lawang (http://Idsejarah.net), Sejarah Candi Pari Sidoarjo (https://situsbudaya.id), Sejarah Candi Cetho Karanganyar - Asal Mula dan Arsitektur Candi (http:// http://sejarahlengkap.com/bangunan/sejarah-candi-cetho) 


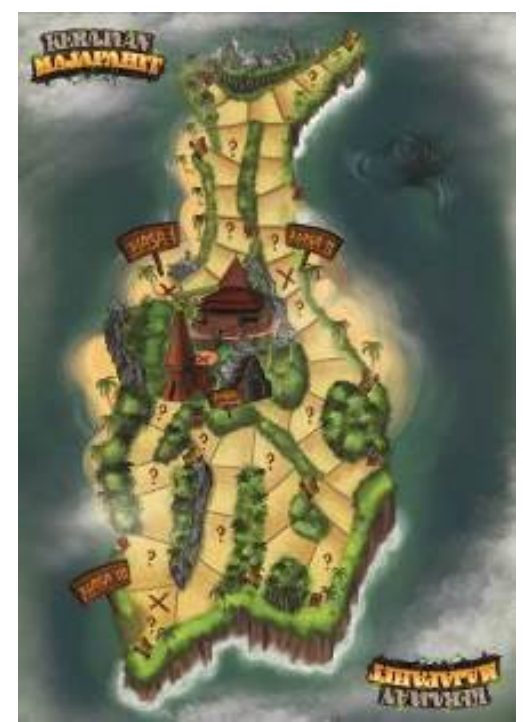

Gambar 7. Papan Permainan (Sumber: Data Penulis, 2108)

Papan permainan mengambil bentuk dari daerah Jawa Timur yang merupakan pusat Kerajaan Majapahit. Papan permainan berukuran 59,4 cm x 84,1 cm ini menampilkan visualisasi pepohonan, tebing dan laut yang dirancang dengan nuansa berkesan 'tua' agar penerapan papan dengan konsep masa lalu muncul lebih kuat.

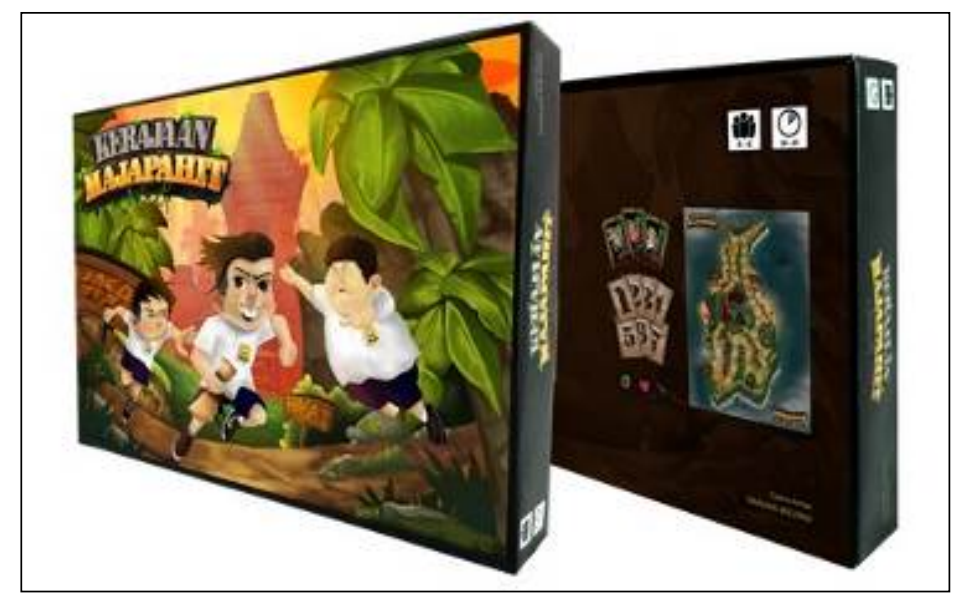

Gambar 8. Desain Kemasan Permainan Papan (Sumber: Data Penulis, 2108)

Ukuran kemasan papan permainan adalah $29,7 \mathrm{~cm}$ x $42 \mathrm{~cm}$. Kemasan dibuat berbentuk balok yang pipih dan dipergunakan untuk menyimpan semua keperluan bermain agar mudah dibawa ke manapun. Selaras dengan permainan yang dirancang, elemen yang tidak dapat dihilangkan adalah buku petunjuk permainan. Dalam buku petunjuk permainan, dirinci secara detail bagaimana cara bermain, aturan-aturan, serta bagaimana cara memenangkan permainan. Visualisasi cover tidak ditampilkan pada tulisan ini. 
Adapun media pendukung untuk memperkenalkan keberadaan permainan ini adalah:

1. Teaser Permainan Papan Kerajaan Majapahit

Teaser merupakan media promosi awal yang dikenalkan dan dapat dilihat pada aplikasi youtube sebagai promosi terbatas dan diunggah pada tautan: https://youtu.be/jn5qWE_1IVU

2. Game Launching (rilis game)

Kegiatan merilis game bertujuan untuk mengedukasi kepada khalayak umum tentang Kerajaan Hindu-Buddha Nusantara dengan mengadakan kegiatan promosi seperti mendemonstrasikan permainan melalui pembukaan stand pribadi.

\section{Poster dan X-Banner}

Poster akan digunakan sebagai media informasi mengenai permainan papan edukasi Kerajaan Hindu-Buddha Nusantara yang akan dipasang pada tempat-tempat bermain dan toko mainan lainnya.

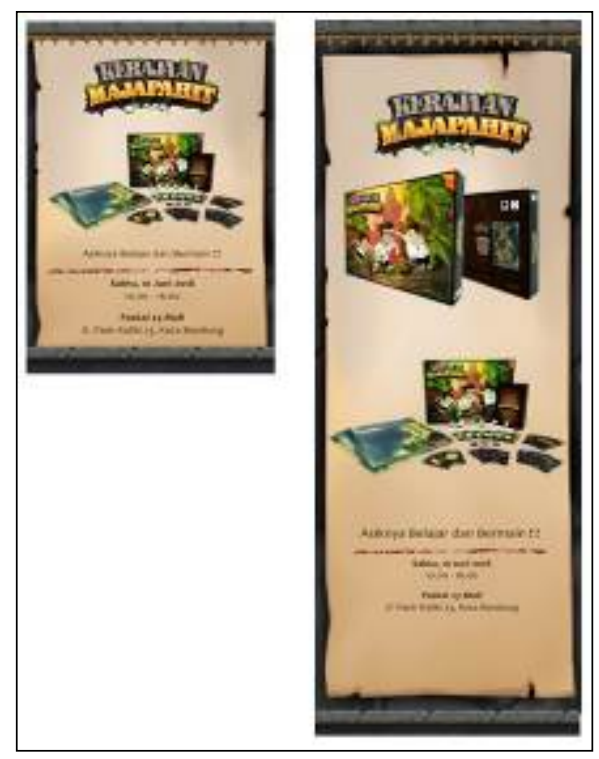

Gambar 9. Desain Poster dan X-Banner (Sumber: Data Penulis, 2108)

\section{PENUTUP}

Pembelajaran sejarah di Sekolah Menengah Pertama pada saat ini masih menggunakan metode yang berfokus pada guru. Hal ini karena banyaknya materi pembelajaran yang padat, rumit dan dianggap terlalu luas. Kepenatan dalam menjalani proses pembelajaran mengakibatkan siswa menjadi jenuh dan bosan. Berdasarkan beberapa teori yang dirujuk, maka media interaktif berupa permainan papan merupakan sarana yang tepat untuk menjadi media bantu pembelajaran sejarah sehingga menjadi menyenangkan. 
Interaktivitas yang menjadi andalan dalam media permainan merupakan kunci dari variasi metode pembelajaran yang didasarkan pada respon stimulus para pemainnya, selain itu, permainan menjadikan aktivitas antar siswa yang sebaya menjadi positif.

Perkembangan zaman memungkinkan adanya penambahan teknologi dalam permainan papan yang bersifat tradisional (dalam arti belum digital atau tidak berbentuk video games yang lebih populer). Augmented Reality dipilih karena dapat menjadi tambahan elemen asosiatif yang membantu daya ingat siswa yang bermain.

Topik yang diambil pada perancangan permainan papan ini adalah Kerajaan Majapahit sebagai perwakilan dari Kerajaan Hindu-Buddha di Nusantara. Selanjutnya, terbuka kesempatan untuk dapat mengembangkan permainan dengan gameplay serupa untuk kerajaan-kerajaan Hindu-Buddha lain yang memiliki rentang waktu panjang dan dengan konteks cerita yang rumit.

\section{DAFTAR PUSTAKA}

Charles Wallschlaeger, C. B.-S. (1992). Basic Visual Concepts And Principles For Artist Architects and Designers (1st ed.). English: McGraw-Hill Humanities/ Social Sciences/ Languages.

DeVries, R. (2000). Vygotsky, Piaget, and Education: a reciprocal assimilation of theories and educational practices. New Ideas in Psychology, 18(2-3), 187-213. doi:https://doi.org/10.1016/S0732-118X(00)00008-8

Fauziah, N. m. (2013). Faktor Penyebab Kejenuhan Belajar Sejarah Kebudayaan Islam (SKI) pada Siswa Kelas XI Jurusan Keagamaan di Man Tempel Sleman. Jurnal Pendidikan Agama Islam UIN Sunan Kalijaga, X (No. 1, Juni 2013), 99-108.

Kevin Leyton-Brown, Y. S. (2008). Essentials of Game Theory: A Concise Multidisciplinary Introduction. Synthesis lectures on Artificial Intelligence and Machine Learning. Essentials of Game Theory: A Concise Multidisciplinary Introduction

Id Sejarah.net. (2016). Candi Wringin Lawang (Gerang Istana Kerajaan Majapahit). https://www.idsejarah.net/2016/08/candi-wringin-lawang-gerbang-istana.html

Informasi Situs Budaya Indonesia. (-). Sejarah Candi Pari Sidoarjo. https://situsbudaya.id/sejarah-candi-pari-sidoarjo/

Perpustakaan Nasional Republik Indonesia (2008). Kepustakaan Candi. http://candi.perpusnas.go.id/

Sejarahlengkap.com. (2016). Sejarah Candi Cetho Karanganyar - Asal Mula dan Arsitektur Candi. http://sejarahlengkap.com/bangunan/sejarah-candi-cetho

Synthesis Lectures on Artificial Intelligence and Machine Learning, 2008, Vol. 2, No. 1 , Pages 1-88. (https://doi.org/10.2200/S00108ED1V01Y200802AIM003).

Nelly Indriani Widiastuti, I. S. (2012). Membangun Game Edukasi Sejarah Walisongo. Jurnal IImiah Komputer dan Informatika (KOMPUTA), 1 (No. 2, Oktober 2012), 41- 48. 